\title{
Attenuation of malignant phenotypes of breast cancer cells through eIF2 $\alpha$-mediated downregulation of Rac1 signaling
}

\author{
KAZUNORI HAMAMURA $^{1}$, KAZUMASA MINAMI ${ }^{2}$, NANCY TANJUNG ${ }^{1}$, QIAOQIAO WAN $^{1}$, \\ MASAHIKO KOIZUMI $^{3}$, NARIAKI MATSUURA ${ }^{2}$, SUNGSOO NA $^{1}$ and HIROKI YOKOTA ${ }^{1,4}$
}

\author{
${ }^{1}$ Department of Biomedical Engineering, Indiana University Purdue University Indianapolis, Indianapolis, IN 46202, USA; \\ ${ }^{2}$ Department of Functional Diagnostic Science, Osaka University Graduate School of Medicine; ${ }^{3}$ Division of Medical Physics, \\ Oncology Center, Osaka University Hospital, Osaka University Medical School, Suita, Osaka 565-0871, Japan; \\ ${ }^{4}$ Department of Anatomy and Cell Biology, Indiana University School of Medicine, Indianapolis, IN 46202, USA
}

Received December 27, 2013; Accepted February 7, 2014

DOI: $10.3892 /$ ijo.2014.2366

\begin{abstract}
Blocking dephosphorylation of eukaryotic translation initiation factor $2 \alpha$ (eIF $2 \alpha$ ) is reported to alter proliferation and differentiation of various cells. Using salubrinal and guanabenz as an inhibitory agent of dephosphorylation of eIF $2 \alpha$, we addressed a question whether an elevated level of phosphorylated eIF $2 \alpha$ attenuates malignant phenotypes of triple negative breast cancer cells (TNBCs) that lack estrogen receptor, progesterone receptor and human epidermal growth factor receptor-2. We determined effects of salubrinal and guanabenz on in vitro phenotype of 4T1 mammary tumor cells and MDA-MB-231 human breast cancer cells and evaluated their effects on in vivo tumor growth using BALB/c mice injected with $4 \mathrm{~T} 1$ cells. The results revealed that these agents block the proliferation and survival of 4T1 and MDA-MB-231 cells, as well as their invasion and motility. Silencing eIF2 $\alpha$ revealed that eIF $2 \alpha$ is involved in the reduction in invasion and motility. Furthermore, salubrinal-driven inactivation of Rac1 was suppressed in the cells treated with eIF $2 \alpha$ siRNA, and treatment with Rac1 siRNA reduced cell invasion and motility. In vivo assay revealed that subcutaneous administration of salubrinal reduced the volume and weight of tumors induced by $4 \mathrm{~T} 1$ cells. Collectively, the results indicate that these agents can attenuate malignant phenotype and tumor growth of breast cancer cells through the eIF $2 \alpha$-mediated Rac1 pathway. Since salubrinal and guanabenz are known to inhibit bone resorption, this study provides a potential use of eIF $2 \alpha$-mediated Rac1 regulation in suppressing the growth and metastasis of breast cancer.
\end{abstract}

Correspondence to: Dr Kazunori Hamamura, Department of Biomedical Engineering, Indiana University Purdue University Indianapolis, 723 West Michigan Street, Indianapolis, IN 46202 USA

E-mail: hamamurk@iupui.edu

Key words: breast cancer, eIF2 $\alpha$, Rac1, salubrinal, guanabenz

\section{Introduction}

Various environmental stresses such as oxidation, nutrient deprivation, radiation, and stress to the endoplasmic reticulum induce the integrated stress response in which the elevated phosphorylation level of eukaryotic translation initiation factor $2 \alpha(\mathrm{eIF} 2 \alpha)$ may stimulate cellular apoptosis $(1,2)$. In response to mild stresses, the phosphorylation of eIF $2 \alpha$ attenuates translational efficiency and activates the prosurvival signaling (3). However, in response to severe stress, the phosphorylated eIF $2 \alpha$ (eIF $2 \alpha-p)$ promotes apoptosis $(3,4)$. Salubrinal, a synthetic chemical agent known to elevate the level of eIF $2 \alpha-p$, is considered as a cytoprotective agent as well as an agent to stimulate apoptosis depending on the stress environments and cell types (5). For instance, it is reported that salubrinal could protect against tunicamycin induced cardiomyocyte apoptosis (6). On the contrary, administration of salubrinal to leukemic and chondrosarcoma cells is reported to stimulate apoptosis $(7,8)$. Nonetheless, few studies have been conducted to examine the effect of salubrinal on breast cancer cells.

Breast cancer accounts for $25 \%$ of all cancers in women and its therapeutic strategy heavily depends on the expression levels of three marker genes such as estrogen receptor (ER), progesterone receptor $(\mathrm{PgR})$ and human epidermal growth factor receptor-2 (HER2). When cancer cells exhibit a high expression level of ER and/or PgR, hormonal treatments would be a viable option (9). For cancer cells with an overexpressed level of HER2, treatments with HER2-targeted drugs such as trastuzumab and lapatinib are potentially effective (10). A lack of expression of all three gene products, however, defines a triple negative breast cancer (TNBC) (11-13) that presents a challenge in prognosis and requires a novel treatment option.

In this study, we addressed the question: does administration of salubrinal attenuate the malignant in vitro phenotype of TNBCs? If yes, what is the mechanism of salubrinal's action and does its administration to mice injected with TNBCs suppress in vivo tumor growth? In response to administration of salubrinal, we examined in vitro phenotype of 4T1 mammary tumor cells and MDA-MB-231 human breast cancer cells (14-16). We also employed guanabenz, another synthetic drug 
known to elevate eIF $2 \alpha$-p by inhibiting de-phosphorylation of eIF $2 \alpha-p$ (17). In order to examine the involvement of eIF $2 \alpha$, silencing by RNA interference was conducted using siRNA specific to eIF $2 \alpha$. Furthermore, the potential linkage between regulation of eIF $2 \alpha$ and Racl GTPase in cell invasion and motility was evaluated using siRNA specific to Racl GTPase. We also employed a fluorescence resonance energy transfer (FRET) technique and evaluated Racl activity in response to salubrinal. To test the effects of salubrinal in vivo, 4T1 mammary tumor cancer cells were injected to mice and suppression of tumor growth was analyzed.

\section{Materials and methods}

Cell culture. 4T1 mouse mammary tumor cells and MDA-MB-231 human breast cancer cells were cultured in DMEM containing $10 \%$ fetal bovine serum and antibiotics $(50 \mathrm{U} / \mathrm{ml}$ penicillin and $50 \mu \mathrm{g} / \mathrm{ml}$ streptomycin; Life Technologies, Grand Island, NY, USA). Cells were maintained at $37^{\circ} \mathrm{C}$ and $5 \% \mathrm{CO}_{2}$ in a humidified incubator. Responses to administration of $10-50 \mu \mathrm{M}$ salubrinal (18) or 5-50 $\mu \mathrm{M}$ guanabenz acetate (Tocris Bioscience, Ellisville, MO, USA) were evaluated using assays for MTT, adhesion, invasion and motility.

MTT assay. Cells (5x10²/well) were seeded in 96-well plates, and the reduction of MTT to formazan was evaluated by measuring the absorbance at $570 \mathrm{~nm}$ with a plate reader (EL800, BioTek, Winooski, VT, USA).

Cell adhesion assay. Ninety-six well plates were coated with poly-L-lysine, fibronectin, laminin (Sigma-Aldrich, St. Louis, MO, USA) or type I collagen (BD Biosciences, Bedford, MA, USA) for $2 \mathrm{~h}$. The plates were then incubated with non-fat dry milk, followed by washing with PBS and serum-free culture medium. Cells $\left(1 \times 10^{4} /\right.$ well $)$ were added on the plate, and after $30 \mathrm{~min}$ and $3 \mathrm{~h}$ the attached cells were stained with $0.04 \%$ crystal violet (Sigma-Aldrich) for $10 \mathrm{~min}$ at room temperature. The wells were washed with PBS, and DMSO was added. Absorbance at $550 \mathrm{~nm}$ was measured using the plate reader.

In vitro invasion assay. An invasion assay was performed with a Boyden chamber as described previously (19), with minor modifications. In brief, Matrigel (BD Biosciences) was diluted with ice-cold PBS $(100 \mu \mathrm{g} / \mathrm{ml})$. Matrigel $(600 \mu \mathrm{l})$ was added to each filter (polyethylene terephthalate membrane, $8-\mu \mathrm{m}$ pore size, $23.1 \mathrm{~mm}$ in diameter, Falcon) and left to polymerize overnight. Prior to assembling the chamber unit, the lower chamber (6-well plate, Falcon) was filled with culture medium consisting of salubrinal or guanabenz. Cells (1-4x $10^{5} /$ well) were added to the culture medium with salubrinal or guanabenz in the upper chamber and incubated for $24 \mathrm{~h}$. The cells on the filter surface were stained with Giemsa (Sigma-Aldrich) and the number of cells was counted under a microscope.

Two-dimensional motility assay. To evaluate 2-dimensional motility, a wound healing scratch motility assay was carried out as described previously (20). In brief, cells were plated in 12-well plates or 6-cm dishes (Falcon) and on the next day, scratching was performed using a plastic tip. The areas newly occupied with cells in the scratched zone were determined every $3 \mathrm{~h}$ up to $24 \mathrm{~h}$ using images obtained by a microscope, which were scanned with Adobe Photoshop (CS2, Adobe Systems, San Jose, CA, USA) and quantified with ImageJ.

Western blot analysis. Cells were lysed in a radioimmunoprecipitation assay (RIPA) buffer containing protease inhibitors (Santa Cruz Biotechnology, Santa Cruz, CA, USA) and phosphatase inhibitors (Calbiochem, Billerica, MA, USA). Isolated proteins were fractionated using 10-15\% SDS gels and electro-transferred to Immobilon-P membranes (Millipore, Billerica, MA, USA). The membrane was incubated for $1 \mathrm{~h}$ with primary antibodies followed by $45 \mathrm{~min}$ incubation with goat anti-rabbit or anti-mouse IgG conjugated with horseradish peroxidase (Cell Signaling, Danvers, MA, USA). We used antibodies against eIF $2 \alpha$, caspase 3 , cleaved caspase (Cell Signaling), Rac1 (Millipore), and $\beta$-actin (Sigma). Protein levels were assayed using a SuperSignal west femto maximum sensitivity substrate (Thermo Scientific, Waltham, MA, USA), and signal intensities were quantified with a luminescent image analyzer (LAS-3000, Fuji Film, Tokyo, Japan).

Knockdown of eIF $2 \alpha$ and Racl by siRNA. Cells were treated with siRNA specific to eIF2 $\alpha$ and Rac1 (Life Technologies). Selected target sequences for knockdown of eIF2 $\alpha$ and Rac1 were: eIF2 $\alpha, 5^{\prime}$-CGG UCA AAA UUC GAG CAG A-3', and Rac1, 5'-GCA UUU CCU GGA GAG UAC A -3'; and as a non-specific control, a negative siRNA (Silencer Select no. 1, Life Technologies) was used. Cells were transiently transfected with siRNA for eIF $2 \alpha$, Racl or control in Opti-MEM I medium with Lipofectamine RNAiMAX (Life Technologies). Six hours later, the medium was replaced by regular culture medium. The efficiency of silencing was assessed with immunoblotting $48 \mathrm{~h}$ after transfection.

Fluorescence resonance energy transfer (FRET). To visualize Rac1 activity in response to salubrinal, FRET imaging was conducted using a cyan fluorescent protein (CFP)-yellow fluorescent protein (YFP) Racl biosensor. The filter sets (Semrock) were chosen for CFP excitation at $438 \pm 24 \mathrm{~nm}$ (center wavelength \pm bandwidth), CFP emission at $483 \pm 32 \mathrm{~nm}$, and YFP emission at $542 \pm 27 \mathrm{~nm}$. Time-lapse images were acquired at an interval of 5 min using a fluorescence microscope (Nikon, Tokyo, Japan). The level of Rac1 activity was determined by computing an emission ratio of YFP/CFP for individual cells using NIS-Elements software (Nikon).

In vivo tumor growth. Experimental procedures were approved by the Indiana University Animal Care and Use Committee and were in compliance with the Guiding Principles in the Care and Use of Animals endorsed by the American Physiological Society. Five mice were housed per cage, and fed with mouse chow and water ad libitum. Thirtyfive BALB/c female mice (6 weeks, Harlan Laboratories) were used. Mice received subcutaneous injection of 4T1 mouse mammary tumor cells $\left(10^{6}\right.$ cells in $100 \mu \mathrm{l}$ PBS $)$ to the abdomen on day 1 . Salubrinal $(25 \mu \mathrm{g})$ was administered 

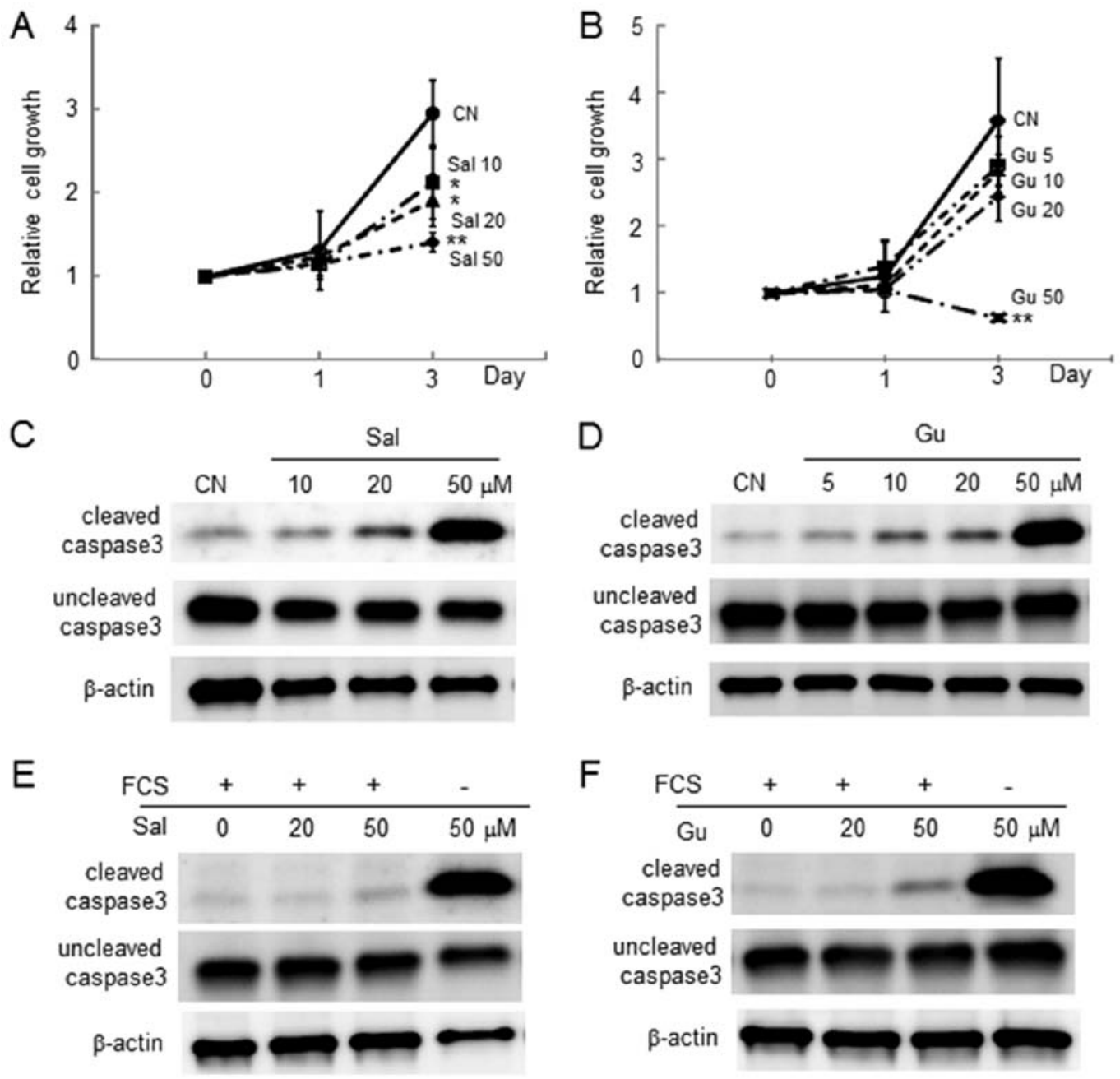

Figure 1. Inhibitory effects of salubrinal and guanabenz in proliferation and survival of $4 \mathrm{~T} 1$ cells. The single and double asterisks indicate $\mathrm{p}<0.05$ and $\mathrm{p}<0.01$, respectively. CN, control; Sal, salubrinal; Gu, guanabenz; and FCS, fetal calf serum. (A) Relative cell growth in response to 10,20 or $50 \mu \mathrm{M}$ salubrinal. (B) Relative cell growth in response to 5,10,20 or 50 $\mu \mathrm{M}$ guanabenz. (C) Dose-dependent elevation of cleaved caspase 3 to 10-50 $\mu \mathrm{M}$ salubrinal in the absence of serum. (D) Dose-dependent elevation of cleaved caspase 3 to 5-50 $\mu \mathrm{M}$ guanabenz in the absence of serum. (E) Reduced elevation of cleaved caspase 3 to salubrinal in the presence of $10 \%$ serum. (F) Reduced elevation of cleaved caspase 3 to guanabenz in the presence of $10 \%$ serum.

subcutaneously into the area of cell injection every day, while the control animals received a vehicle. The animals were sacrificed on day 20, and the volume and weight of tumors were determined. The tumor volume was calculated as (long diameter) $\mathrm{x}$ (short diameter $)^{2} / 2$.

Statistical analysis. Three or four-independent experiments were conducted and data were expressed as mean \pm SD. For comparison among multiple samples, ANOVA followed by post hoc tests was conducted. Statistical significance was set at $\mathrm{p}<0.05$. The single and double asterisks in the figures indicate $\mathrm{p}<0.05$ and $\mathrm{p}<0.01$.

\section{Results}

Inhibitory effects of salubrinal and guanabenz in proliferation and survival of 4 T1 cells. The MTT assay revealed that in response to 10,20 and $50 \mu \mathrm{M}$ salubrinal, the number of live 4T1 cells was reduced in a dose-dependent manner (Fig. 1A). The number of live cells was also decreased by
$50 \mu \mathrm{M}$ guanabenz (Fig. 1B). Consistent with the MTT results, both salubrinal and guanabenz elevated the level of cleaved caspase 3 in the absence and presence of $10 \%$ serum in the culture medium, respectively (Fig. 1C-F).

Undetectable changes in cell adhesion by salubrinal and guanabenz in $4 T 1$ cells. The surface was coated with poly-Llysine, type I collagen, fibronectin, and laminin, and the effects of salubrinal and guanabenz on cell adhesion were examined. The absorbance reading, which indicated the number of adherent cells on the coated surface, did not significantly change in the presence and absence of salubrinal and guanabenz $30 \mathrm{~min}$ and $3 \mathrm{~h}$ after cell incubation, respectively (data not shown).

Dose-dependent reduction in cell invasion by salubrinal and guanabenz in $4 T 1$ cells. The number of cells invaded through the filter coated with Matrigel was significantly reduced by administration of salubrinal and guanabenz regardless of the presence of serum in the medium in a dose-dependent manner (Fig. 2A-C). 
A
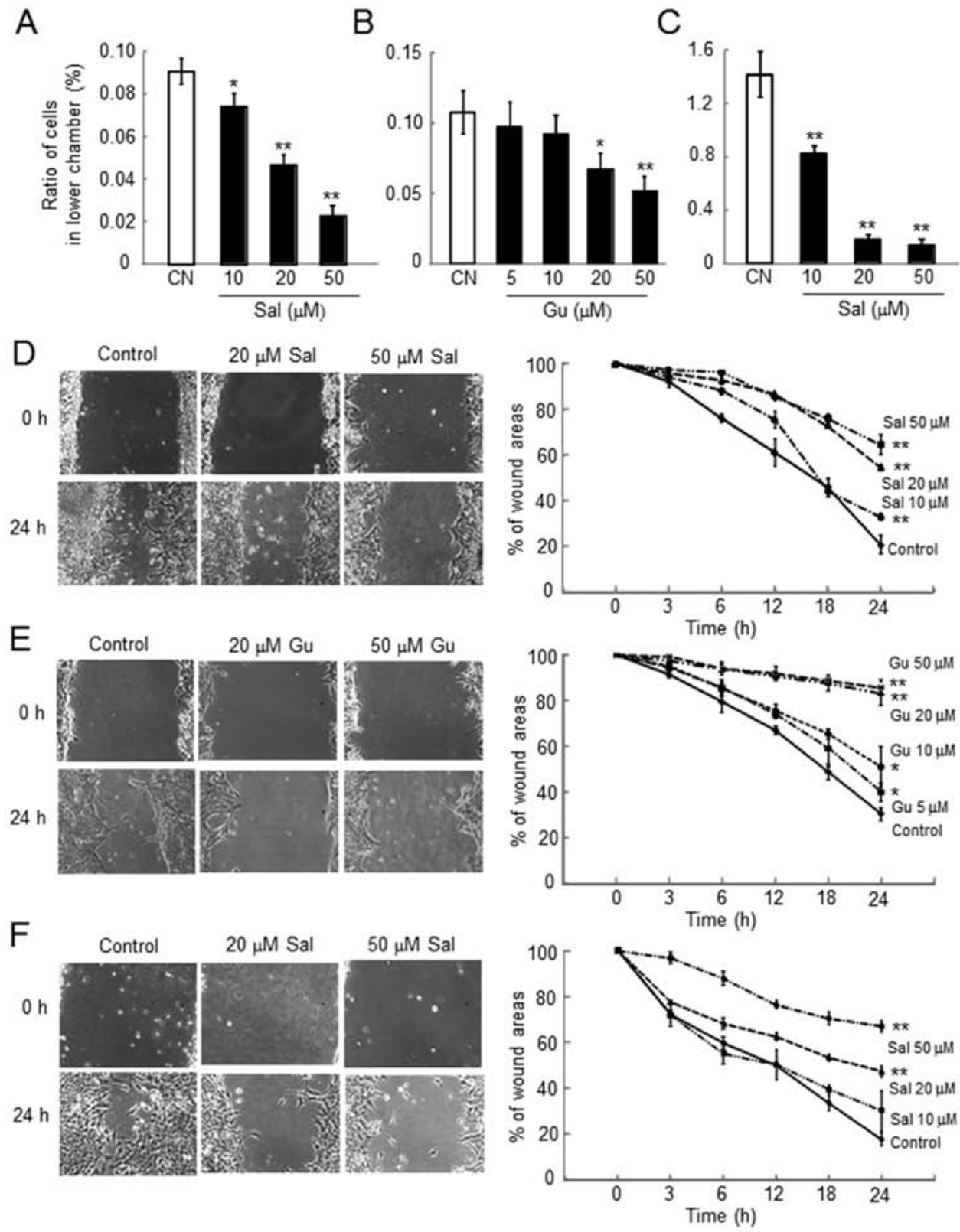

Figure 2. Dose-dependent reduction in invasion and reduction in motility of $4 \mathrm{~T} 1$ cells. The single and double asterisks indicate $\mathrm{p}<0.05$ and $\mathrm{p}<0.01$, respectively. $\mathrm{CN}$, control; Sal, salubrinal; and Gu, guanabenz. (A) Percent of the invaded cells in response to 10, 20 or $50 \mu \mathrm{M}$ salubrinal in the absence of serum. (B) Percent of the invaded cells in response to 5, 10, 20 or $50 \mu \mathrm{M}$ guanabenz in the absence of serum. (C) Percent of the invaded cells in response to salubrinal in the presence of $10 \%$ serum. (D) Reduction in cell motility by 20 or $50 \mu \mathrm{M}$ salubrinal in $24 \mathrm{~h}$ in the absence of serum. (E) Reduction in cell motility by 20 or $50 \mu \mathrm{M}$ guanabenz in $24 \mathrm{~h}$ in the absence of serum. (F) Sustained reduction in cell motility by salubrinal in the presence of $10 \%$ serum.

Reduction in cell motility by salubrinal and guanabenz in $4 T 1$ cells. Using the scratch-wound assay, the wound area was determined as an indicator of cell motility in which a reduction in motility corresponded with a decrease in wound healing. In response to both salubrinal and guanabenz, cell motility was reduced in a dose-dependent manner (Fig. 2D-F). The results with salubrinal were not affected by the presence of serum in the culture medium.

Reduction in proliferation, invasion, survival, and motility in MDA-MB-231 cells. Consistent with the results in 4T1 mouse mammary tumor cells, we observed reduction in proliferation, invasion, survival and motility in MDA-MB-231 human breast cancer cells (Fig. 3).
Involvement of eIF $2 \alpha$ in salubrinal-driven reduction in cell invasion and motility in $4 T 1$ cells. Cell invasion and motility in response to salubrinal were examined using the cells transiently transfected with eIF $2 \alpha$ siRNA (Fig. 4A). Compared to the cells transfected with non-specific control (NC) siRNA, salubrinal-driven reduction in cell invasion was significantly suppressed in the cells treated with eIF2 $\alpha$ siRNA (Fig. 4B). However, in the control cells treated with NC siRNA, the cell invasion was reduced by salubrinal in a dose-dependent manner. Furthermore, salubrinal-driven reduction in cell motility was also suppressed by eIF $2 \alpha$ siRNA (Fig. 4C and D).

Inactivation of Racl GTPase by $20 \mu \mathrm{M}$ salubrinal in $4 T 1$ cells and MDA-MB-231 cells. To evaluate a potential involve- 

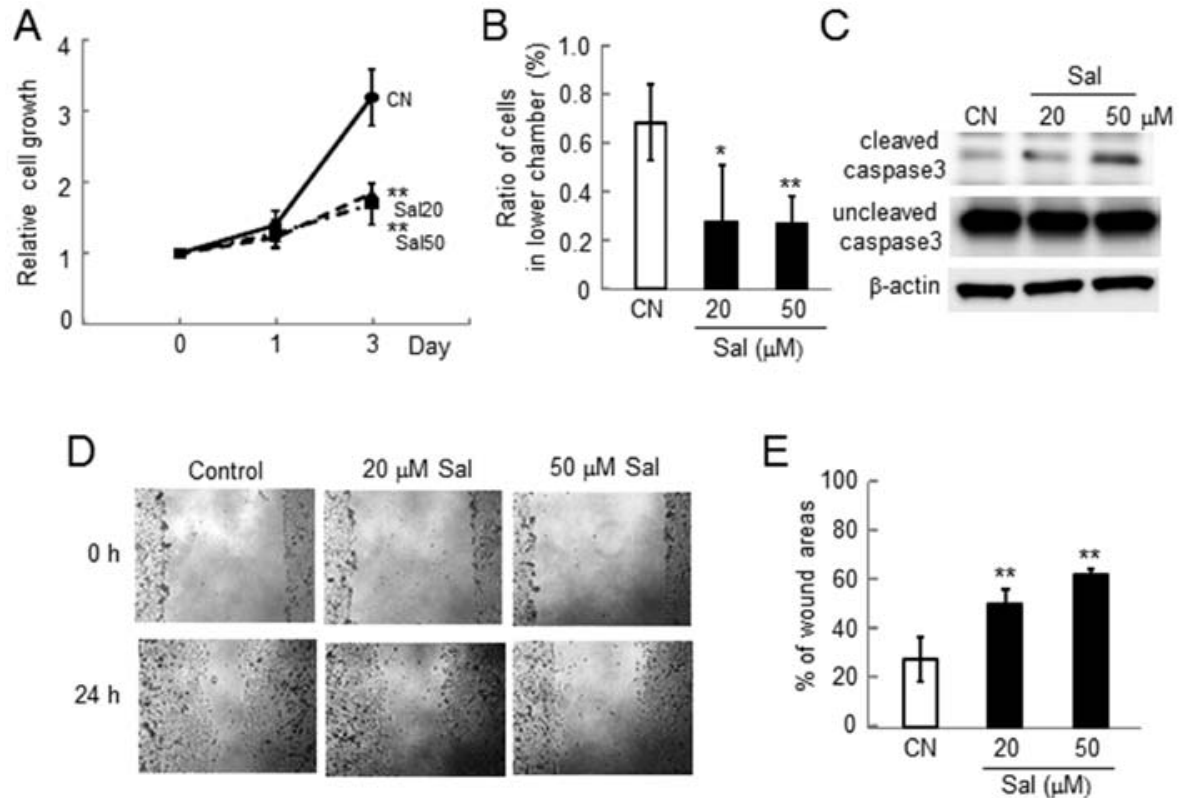

Figure 3. Inhibitory effects of salubrinal in proliferation, invasion, survival, and motility of MDA-MB-231 cells. The single and double asterisks indicate $\mathrm{p}<0.05$ and $\mathrm{p}<0.01$, respectively. CN, control; and Sal, salubrinal. (A) Relative cell growth in response to 20 or $50 \mu \mathrm{M}$ salubrinal. (B) Reduction in cell invasion by 20 or $50 \mu \mathrm{M}$ salubrinal in $24 \mathrm{~h}$ in the absence of serum. (C) Dose-dependent elevation of cleaved caspase 3 to 20 or $50 \mu \mathrm{M}$ salubrinal in the absence of serum. (D and E) Reduction in cell motility by 20 or $50 \mu \mathrm{M}$ salubrinal in $24 \mathrm{~h}$ in the presence of $10 \%$ serum.

A

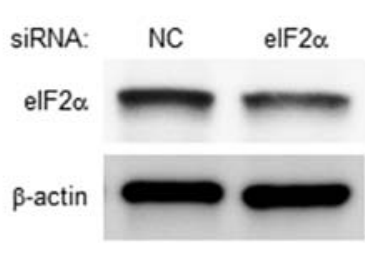

C

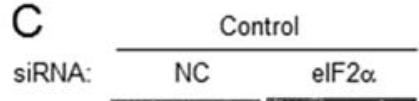

$\mathrm{Oh}$

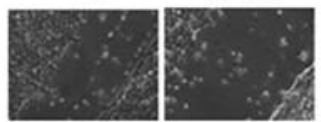

$24 \mathrm{~h}$

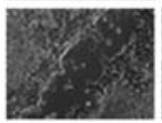

B
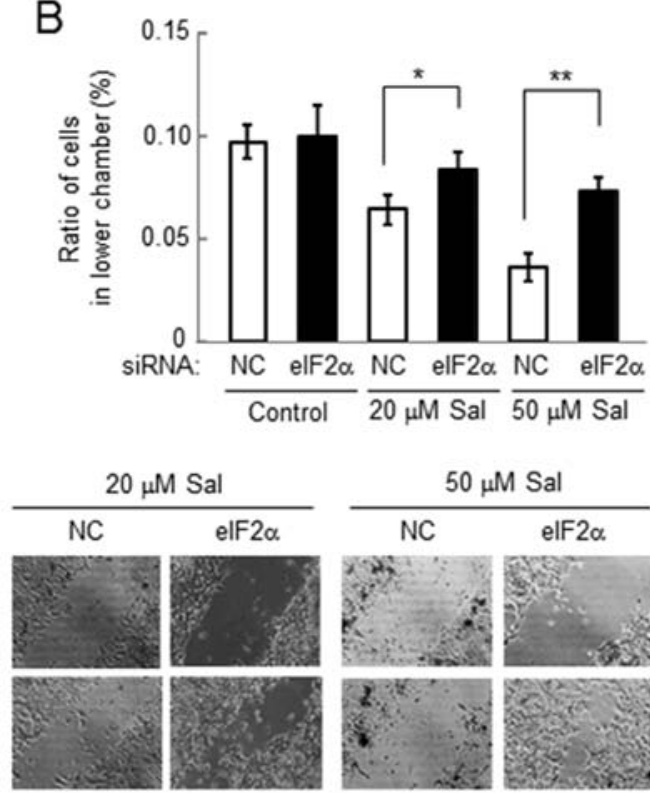

$\mu \mathrm{M}$ Sal

elF $2 \alpha$

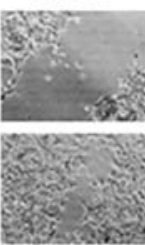

$\mathrm{D}$

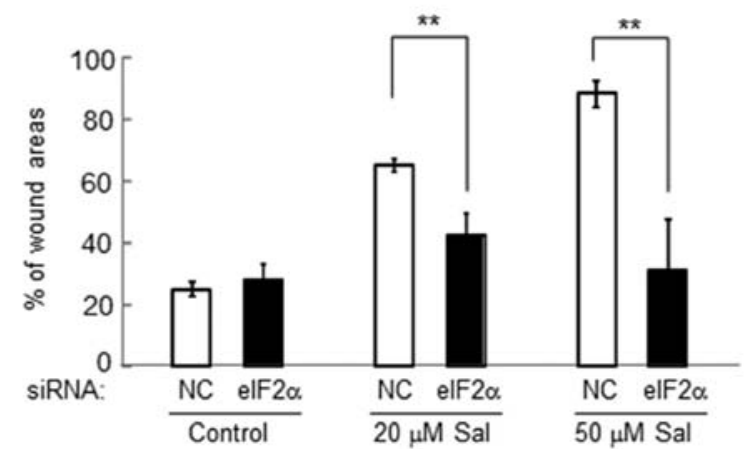

Figure 4. Involvement of eIF $2 \alpha$ in salubrinal-driven reduction in cell invasion and motility of $4 \mathrm{~T} 1$ cells. Salubrinal was given at 20 or $50 \mu \mathrm{M}$. The single and double asterisks indicate $\mathrm{p}<0.05$ and $\mathrm{p}<0.01$, respectively. Note that NC designates the samples treated with the non-specific control siRNA. Sal, salubrinal. (A) Reduction in the protein level of eIF2 $\alpha$ by RNA interference. (B) Partial suppression of salubrinal-driven reduction in cell invasion by eIF2 $\alpha$ siRNA. (C and D) Suppression of salubrinal-driven reduction in cell motility (elevation of the wound areas) by eIF2 $\alpha$ siRNA. 
A
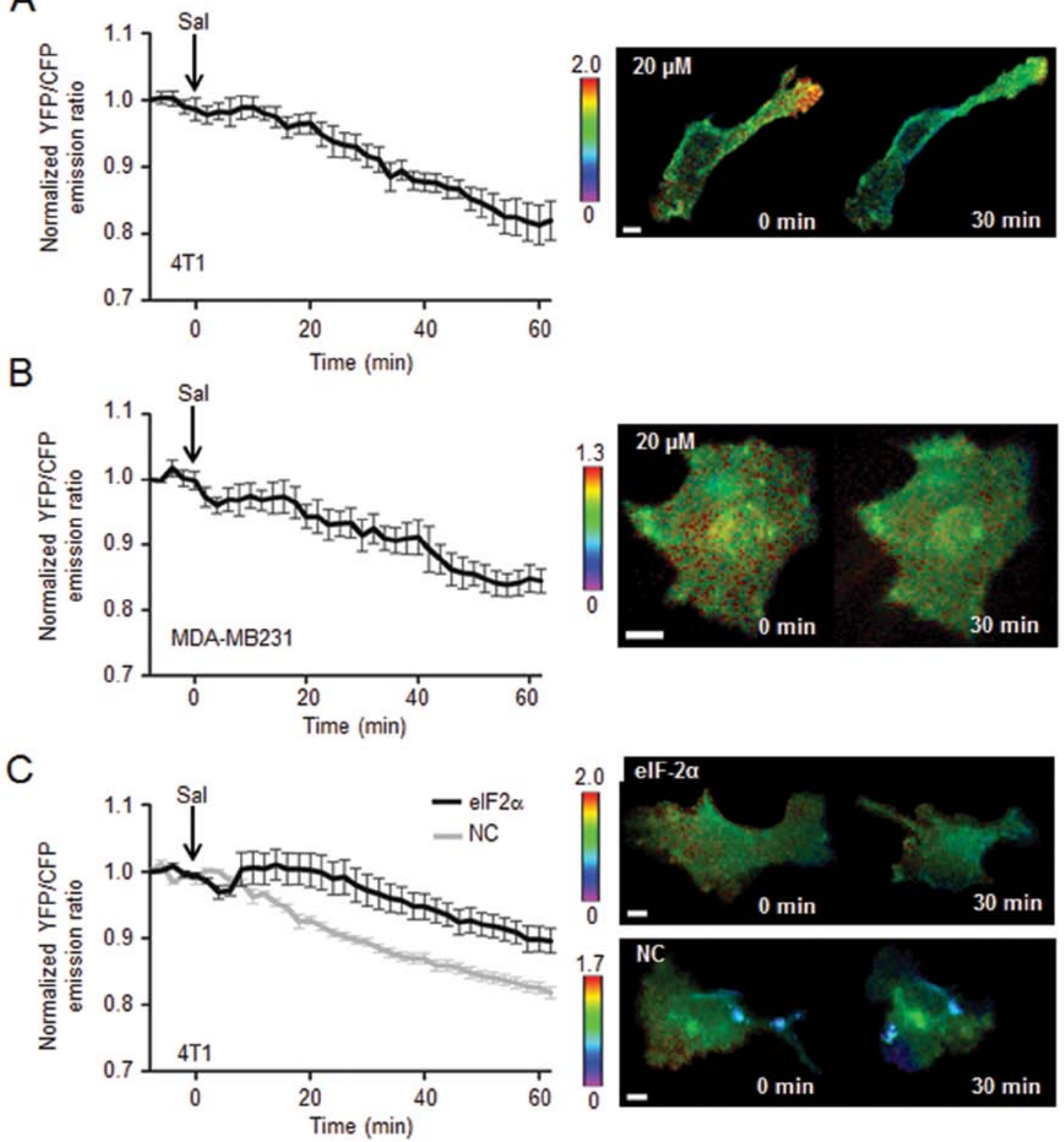

Figure 5. FRET-based detection of inactivation of Rac1 GTPase in response to $20 \mu \mathrm{M}$ salubrinal. In live cell imaging, the color bar represents the emission ratio of YFP/CFP, an index of Rac1 activation and the arrow indicates the commencement time $(\mathrm{t}=0)$ for administration of salubrinal. Scale bar, $10 \mu \mathrm{m}$. (A) Normalized Rac1 activity in 4T1 cells. (B) Normalized Rac1 activity in MDA-MB-231 cells. (C) Normalized Rac1 activity in the presence of eIF2 $\alpha$ siRNA or non-specific control (NC) siRNA in 4T1 cells.

ment of Rac1 through eIF $2 \alpha$-mediated signaling, the effect of salubrinal on activity of Rac1 GTPase was examined using FRET-based single cell imaging. In response to $20 \mu \mathrm{M}$ salubrinal, the emission ratio of YFP/CFP was decreased in 4T1 cells as well as MDA-MB-231 cells, indicating that administration of salubrinal reduced the activity level of Rac1 (Fig. 5A and B). The FRET analysis was also conducted using 4T1 cells transfected with eIF2 $\alpha$ siRNA, in which salubrinaldriven reduction in Racl activity was significantly suppressed (Fig. 5C).

Reduction in cell growth, invasion and motility by Racl siRNA in $4 T 1$ cells. In order to examine the role of Rac1 in salubrinal-driven suppression of malignant phenotypes, cell growth, invasion and motility was examined using siRNA specific to Racl (Fig. 6A). The result revealed that reduction in the expression level of Racl lowered cell growth and elevated the level of cleaved caspase 3 (Fig. 6B and C). Furthermore, silencing Racl decreased cell invasion as well as cell motility (Fig. 6D and F).

Inhibitory effects of salubrinal in the volume and weight of tumors. Using the in vivo mouse model, the effects of salubrinal on tumor growth were evaluated. A comparison of the tumors isolated from the control mice $(\mathrm{N}=17)$ and the salubrinal-treated mice $(\mathrm{N}=18)$ revealed that the tumor volume (control, $620.1 \pm 271.1 \mathrm{~mm}^{3}$; and salubrinal, $384.5 \pm 248.1 \mathrm{~mm}^{3}$ ) and weight (control, $0.51 \pm 0.21 \mathrm{~g}$; and salubrinal, $0.32 \pm 0.24 \mathrm{~g}$ ) 

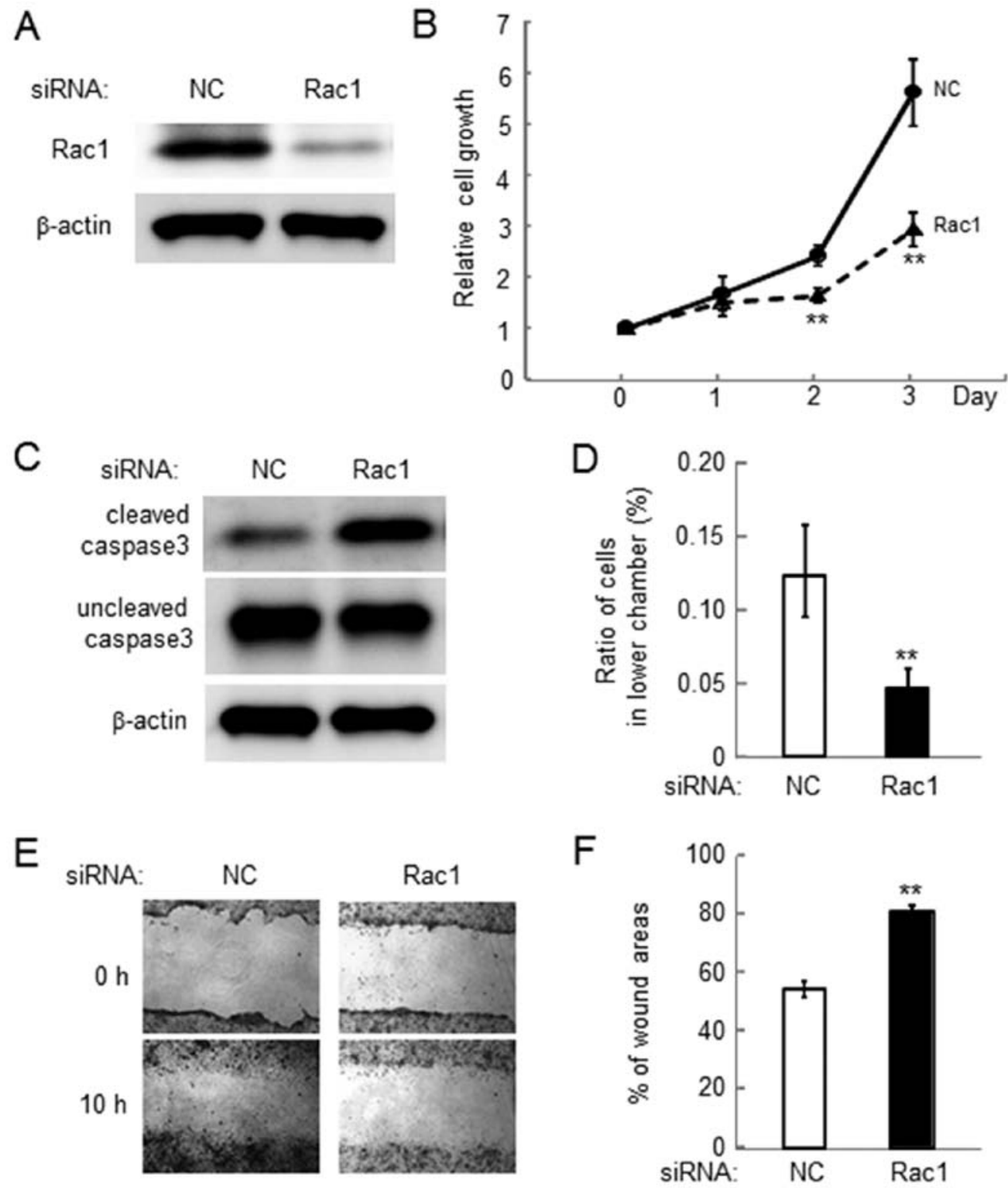

Figure 6. Reduction in cell invasion and motility of 4T1 cells by RNA interference with Rac1 siRNA. Note that NC designates the samples treated with the non-specific control siRNA. The double asterisk indicates $\mathrm{p}<0.01$. (A) Reduction in the protein level of Rac1 by RNA interference. (B) Reduction of cell growth by Rac1 siRNA. (C) Increase in cleaved caspase 3 by Rac1 siRNA. (D) Reduction in cell invasion by Rac1 siRNA. (E and F) Reduction in cell motility by Rac1 siRNA.

were significantly larger in the control group than the salubrinal-treated group (Fig. 7A and B).

\section{Discussion}

We demonstrated in this study that salubrinal has inhibitory effects on the malignant phenotypes of 4T1 mammary tumor cells and MDA-MB-231 breast cancer cells that hold a triple negative phenotype. Salubrinal significantly reduced cellular proliferation, invasion, and migration, although it did not alter cellular adhesion to surfaces coated with poly-L-lysine, type I collagen, fibronectin or laminin. The inhibitory effects were commonly observed in response to salubrinal and guanabenz, both of which elevate the level of p-eIF2 $\alpha$. RNA silencing with eIF2 $\alpha$ siRNA abolished salubrinal driven reduction in Rac1 and RNA silencing with Rac1 siRNA attenuated malignant phenotypes as seen in the responses to salubrinal. Furthermore, in vivo tumor size and weight in $4 \mathrm{~T} 1$ cells injected mice were significantly reduced by daily administration of salubrinal (Fig. 7D).

The elevated level of cleaved caspase 3 indicates that cellular apoptosis is stimulated by salubrinal. An increase in apoptotic death was more significant in the absence of FBS in the medium than that with FBS, suggesting that potency of salubrinal is enhanced in a nutrient poor environment. Previous studies reported that salubrinal could induce either stimulatory or inhibitory effects on cellular death through modulation of the level of p-eIF $2 \alpha(6,7)$. Our data are consistent with a notion that in an abnormal growth condition such as in a solid tumor without well-developed vasculature, the elevation of p-eIF $2 \alpha$ leads to a pro-apoptotic pathway.

Racl GTPase is a regulator of various cellular processes, including cell cycle, motility, invasion and cell-cell adhesion (21). It has been known to play a substantial role in the develop- 

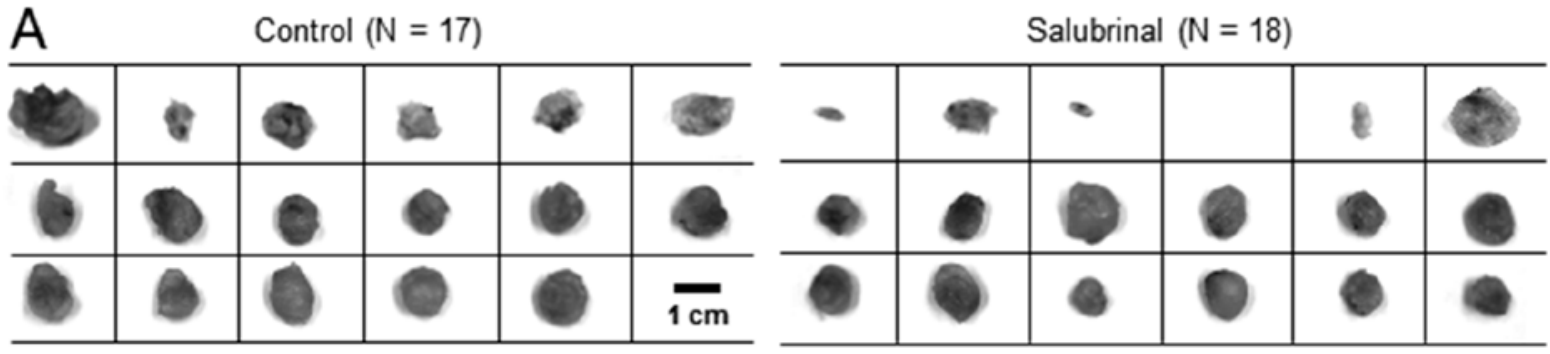

B

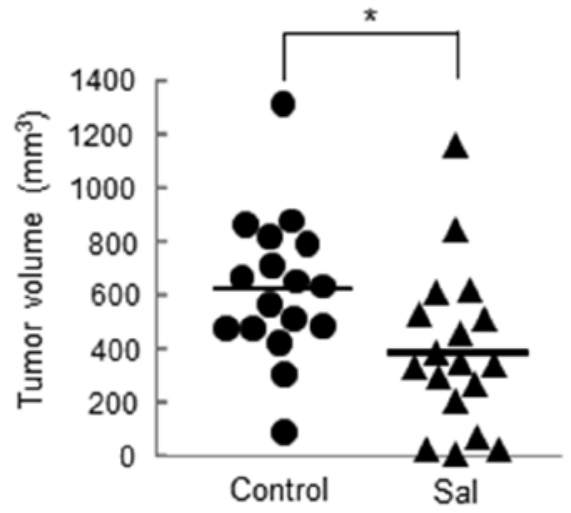

$\mathrm{C}$

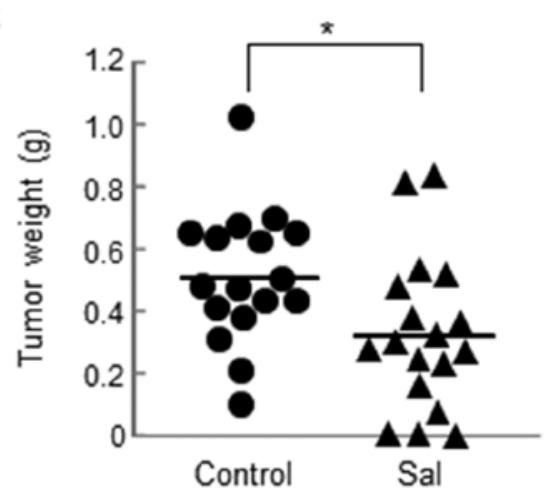

$\mathrm{D}$

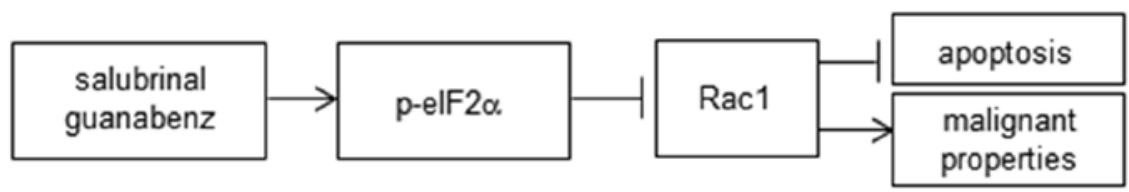

Figure 7. Inhibitory effects of salubrinal on tumor growth with 4T1 cells. (A) Images of harvested tumors in the control and salubrinal-treated groups. (B and C) Comparison of the tumor volume and weight, respectively. The circles and triangles represent the values for the control and salubrinal-treated mice, respectively. The horizontal bars indicate the mean values for each group. $\mathrm{N}=17$ for control and $\mathrm{N}=18$ for the salubrinal-treated mice. Sal, salubrinal. (D) Proposed mechanism of salubrinal's action on breast cancer cells.

ment of various cancers including breast cancer and pancreatic cancer $(22,23)$. It is reported that the Rac-guanine nucleotide exchange factor (GEF) P-Rex1 is an essential stimulator of Rac1 activation, and P-Rex 1 is activated by the phosphatidylinositide 3-kinases (PI3K) pathway (24,25). Furthermore, Rac1 can be activated through integrins, tyrosin-kinase receptors, and various stress factors including mechanical stimulation, and the stress to the endoplasmic reticulum (21). Since salubrinal could relieve the stress to the endoplasmic reticulum, there is a possibility that eIF $2 \alpha$-mediated Rac1 suppression is linked to modulation of stress responses in 4T1 mammary tumor cells. In inflammatory cartilage and chondrocytes, it is also reported that the activity of Racl is reduced by treatment with salubrinal (26). Further analysis is necessary to identify the mechanistic role of eIF2 $\alpha$ in salubrinal-driven regulation of Rac1.

Since 4T1 and MDA-MB-231 cells are considered to be triple negative, the action of salubrinal is indubitably different from that of selective estrogen receptor modulators (SERMs) which target the estrogen receptor. Tamoxifen, for instance, is thought to act as an agonist at the bone and uterus and an antagonist at the breast (9). Unlike salubrinal, however, tamoxifen is not effective for estrogen receptor-negative breast cancer cells. Regarding the involvement of Rac1 in response to salubrinal, it is reported that inhibition of Rac1 using a pharmacological agent (EHT1864) decreases estrogen receptor levels and proliferation of both tamoxifen-sensitive and resistant cells (27). Although the reported study suggests that inhibition of Racl could be a therapeutic strategy for estrogen receptorpositive cells, our study indicates that salubrinal-driven reduction of Rac1 is also effective in attenuating malignant phenotypes of estrogen receptor-negative cells. In this context, MDA-MB-231 cells used in this study have K-Ras mutation and are dependent on Rac1 for growth factor driven invasion and migration (28). Therefore, Racl activity may potentially serve as a biomarker of response to salubrinal.

Approximately $20 \%$ of breast cancer patients are likely to develop metastatic tumors in distant organs such as the lungs, liver, brain and bone (29). In particular, bone is the most common site for metastasis of breast cancer. The current chemotherapy for the treatment of bone metastasis includes administration of SERMs such as tamoxifen, bisphosphonates (e.g., zoledronate, pamidronate and alendronate), and anti-receptor activator of nuclear factor $\kappa-B$ ligand (RANKL) antibody (Denosumab) $(30,31)$. Bisphosphonates are the most commonly used medication to reduce bone resorption, bone destruction and tumor growth. However, it does not stimulate bone formation and it often exhibits side effects such as joint inflammation and avascular osteonecrosis of the jaw (32). Denosumab is reported to reduce bone metastasis, but it effects on tumor growth have to be elucidated. Salubrinal 
and guanabenz, which inhibit the de-phosphorylation of eIF2 $\alpha$ could both stimulate osteoblastgenesis through upregulation of ATF4 and attenuate osteoclastogenesis through downregulation of nuclear factor of activated T-cells, cytoplasmic 1 (NFATc1) $(33,34)$. Since salubrinal was shown to stimulate the growth of new bone and enhance the healing of bone wound, examining its effects on tumor growth would have a significant impact on treatment of breast cancer and bone metastasis.

In conclusion, we demonstrated that an inhibitory agent of dephosphorylation of eIF $2 \alpha$ potentially offers a novel therapeutic strategy for attenuating malignant phenotypes of triple negative breast cancer cells. It was shown to downregulate the activity of Rac1 through eIF2 $\alpha$ mediated signaling. It may prevent not only tumor growth but also bone resorption associated with metastasis to bone.

\section{Acknowledgements}

The authors thank $\mathrm{H}$. Nakshatri for the provision of MDA-MB-231 cells and a critical review of this study, and M. Hamamura for technical support. This study was supported by the Indiana University - Purdue University Indianapolis Research Support Funds Grant and the Japan Society for the Promotion of Science Core-to-Core Program, 23003.

\section{References}

1. Ron D: Translational control in the endoplasmic reticulum stress response. J Clin Invest 110: 1383-1388, 2002.

2. Szegezdi E, Logue SE, Gorman AM and Samali A: Mediators of endoplasmic reticulum stress-induced apoptosis. EMBO Rep 7: 880-885, 2006

3. Hamamura K and Yokota H: Stress to endoplasmic reticulum of mouse osteoblasts induces apoptosis and transcriptional activation for bone remodeling. FEBS Lett 581: 1769-1774, 2007.

4. Hamamura K, Goldring MB and Yokota $\mathrm{H}$ : Involvement of p38 MAPK in regulation of MMP13 mRNA in chondrocytes in response to surviving stress to endoplasmic reticulum. Arch Oral Biol 54: 279-286, 2009.

5. Boyce M, Bryant KF, Jousse C, et al: A selective inhibitor of eIF2 $\alpha$ dephosphorylation protects cells from ER stress. Science 307: 935-939, 2005

6. Liu CL, Li X, Hu GL, et al: Salubrinal protects against tunicamycin and hypoxia induced cardiomyocyte apoptosis via the PERK-eIF2 $\alpha$ signaling pathway. J Geriatr Cardiol 9: 258-268, 2012.

7. Drexler HCA: Synergistic apoptosis induction in leukemic cells by the phosphatase inhibitor salubrinal and proteasome inhibitors. PLoS One 4: e4161, 2009.

8. Koizumi M, Tanjung NG, Chen A, et al: Administration of salubrinal enhances radiation induced cell death of SW1353 chondrosarcoma cells. Anticancer Res 32: 3667-3674, 2012.

9. Osborne CK, Zhao H and Fuqua SA: Selective estrogen receptor modulators: structure, function, and clinical use. J Clin Oncol 18 3172-3186, 2000

10. De Laurentiis M, Cianniello D, Caputo R, et al: Treatment of triple negative breast cancer (TNBC): current options and future perspectives. Cancer Treat Rev 36 (Suppl 3): S80-S86, 2010.

11. Gluz O, Liedtke C, Gottschalk N, Pusztai L, Nitz U and Harbeck N: Triple-negative breast cancer-current status and future directions. Ann Oncol 20: 1913-1927, 2009.

12. Bosch A, Eroles P, Zaragoza R, Vina JR and Lluch A: Triplenegative breast cancer: molecular features, pathogenesis, treatment and current lines of research. Cancer Treat Rev 36: 206-215, 2010

13. Foulkes WD, Smith IE and Reis-Filho JS: Triple-negative breast cancer. N Engl J Med 363: 1938-1948, 2010.
14. Prud'homme GJ, Glinka Y, Toulina A, Ace O, Subramaniam V and Jothy S: Breast cancer stem-like cells are inhibited by a non-toxic aryl hydrocarbon receptor agonist. PLoS One 5: e13831, 2010.

15. Bouquet F, Pal A, Pilones KA, et al: TGF $\beta 1$ inhibition increases the radiosensitivity of breast cancer cells in vitro and promotes tumor control by radiation in vivo. Clin Cancer Res 17: 6754-6765, 2011

16. Kaur P, Nagaraja GM, Zheng $\mathrm{H}$, et al: A mouse model for triple-negative breast cancer tumor-initiating cells (TNBC-TICs) exhibits similar aggressive phenotype to the human disease. BMC Cancer 12: 120, 2012.

17. Tsaytler P, Harding HP, Ron D and Bertolotti A: Selective inhibition of a regulatory subunit of protein phosphatase 1 restores proteostasis. Science 332: 91-94, 2011

18. Niknejad N, Gorn-Hondermann I, Ma L, et al: Lovastatininduced apoptosis is mediated by activating transcription factor 3 and enhanced in combination with salubrinal. Int J Cancer 134: 268-279, 2014

19. Hamamura K, Furukawa K, Hayashi T, et al: Ganglioside GD3 promotes cell growth and invasion through p130Cas and paxillin in malignant melanoma cells. Proc Natl Acd Sci USA 102: 11041-11046, 2005.

20. Shibuya H, Hamamura K, Hotta $\mathrm{H}$, et al: Enhancement of malignant properties of human osteosarcoma cells with disialyl gangliosides GD2/GD3. Cancer Sci 103: 1656-1664, 2012.

21. Sander EE and Collard JG: Rho-like GTPases: Their role in epithelial cell-cell adhesion and invasion. Eur J Cancer 35: 1302-1308, 1999.

22. Wertheimer E, Gutierrez-Uzquiza A, Rosemblit C, Lopez-Haber C, Sosa MS and Kazanietz MG: Rac signaling in breast cancer: a tale of GEFs and GAPs. Cell Signal 24: 353-362, 2012.

23. Heid I, Lubeseder-Martellato C, Sipos B, et al: Early requirement of Rac1 in a mouse model of pancreatic cancer. Gastroenterology 141: 719-730, 2011.

24. Welch HCE, Coadwell WJ, Ellson CD, Ferguson GJ, Andrews SR, Erdjument-Bromage $\mathrm{H}$, et al: P-Rex1, a Ptdlns $(3,4,5) \mathrm{P} 3$ - and G $\beta \gamma$-regulated guanine-nucleotide exchange factor for Rac. Cell 108: 809-821, 2002

25. Yoshizawa M, Kawauchi T, Sone M, et al: Involvement of a Rac activator, $\mathrm{p}-\mathrm{Rex} 1$, in neurotrophin-derived signaling and neuronal migration. J Neurosci 25: 4406-4419, 2005.

26. Shim JW, Hamamura K, Chen A, Wan Q, Na S and Yokota H: Rac1 mediates load-driven attenuation of mRNA expression of nerve growth factor beta in cartilage and chondrocytes. J Musculoskelet Neuronal Interact 13: 372-379, 2013.

27. Rosenblatt AE, Garcia MI, Lyons L, et al: Inhibition of the Rho GTPase, Rac1, decreases estrogen receptor levels and is a novel therapeutic strategy in breast cancer. Endocr Relat Cancer 18: 207-219, 2011.

28. Yang Y, Du J, Hu Z, et al: Activation of Rac1-PI3K/Akt is required for epidermal growth factor-induced PAK1 activfation and cell migration in MDA-MB-231 brest cancer cells. J Biomed Res 25: 237-245, 2011.

29. Eckhardt BL, Francis PA, Parker BS and Anderson RL: Strategies for the discovery and development of therapies for metastatic breast cancer. Nat Rev Drug Discov 11: 479-497, 2012.

30. Van Poznak CH, Temin S, Yee GC, et al: American society of clinical oncology executive summary of the clinical practice guideline update on the role of bone-modifying agents in metastatic breast cancer. J Clin Oncol 29: 1221-1227, 2011.

31. Lee BL, Higgins MJ and Goss PE: Denosumab and the current status of bone-modifying drugs in breast cancer. Acta Oncol 51: 157-167, 2012.

32. Marx RE: Pamidronate (Aredia) and zoledronate (Zometa) induced avascular necrosis of the jaws: a growing epidemic. J Oral Maxillofac Sug 61: 1115-1118, 2003.

33. He L, Lee $\mathrm{J}$, Jang $\mathrm{JH}$, et al: Osteoporosis regulation by salubrinal through eIF $2 \alpha$ mediated differentiation of osteoclast and osteoblast. Cell Signal 25: 552-560, 2013.

34. Hamamura K, Tanjung N and Yokota H: Suppression of osteoclastogenesis through phosphorylation of eukaryotic translation initiation factor 2 alpha. J Bone Miner Metab 31: 618-628, 2013 